\title{
Antagonistic Potential of Soil Streptomyces Isolates from Southern Thailand to Inhibit Foodborne Bacterial Pathogens
}

\author{
Waenurama Chemoh (D), ${ }^{1}$ Wahida Bin-Ismail, ${ }^{2}$ and Sawitree Dueramae ${ }^{3}{ }^{3}$ \\ ${ }^{1}$ Department of Microbiology, Faculty of Medicine, Princess of Naradhiwas University, Narathiwat 96000, Thailand \\ ${ }^{2}$ Faculty of Science and Technology, Princess of Naradhiwas University, Narathiwat 96000, Thailand \\ ${ }^{3}$ Department of Applied Microbiology, Institute of Food Research and Product Development, Kasetsart University, \\ Bangkok 10900, Thailand \\ Correspondence should be addressed to Waenurama Chemoh; waenurama.c@pnu.ac.th
}

Received 24 June 2021; Accepted 20 August 2021; Published 30 August 2021

Academic Editor: Clemencia Chaves Lopez

Copyright (c) 2021 Waenurama Chemoh et al. This is an open access article distributed under the Creative Commons Attribution License, which permits unrestricted use, distribution, and reproduction in any medium, provided the original work is properly cited.

\begin{abstract}
Streptomyces are well known for their competence to produce thousands of bioactive secondary metabolites and enzymes. This study aimed to assess the inhibitory activities of crude extracts from diverse Streptomyces collected from rice soils in Narathiwat, Thailand, against foodborne bacterial pathogens. In total, 136 Actinomycete isolates were screened using a cross-streak method for the ability to produce effective metabolites against 5 pathogenic bacteria. Out of these, 19 (13.97\%) isolates had antibacterial activity against at least one tested bacterium. Most of the isolates could strongly suppress the growth of S. aureus ATCC25923 and B. cereus MTCC430 except $P$. aeruginosa ATCC27853. On the basis of morphological, cultural, and biochemical characteristics, all potent isolates exhibited typical features that fitted the genus Streptomyces. Two of the 7 selected ethyl acetate crude extracts had good antagonistic activity against S. aureus ATCC25923 and B. cereus MTCC430 when tested using the agar well diffusion assay. Furthermore, minimum inhibitory concentration (MIC) and minimum bactericidal concentration (MBC) values of the 2 extracts evaluated using the colorimetric broth microdilution method ranged from 256 to $>1,024 \mu \mathrm{g} / \mathrm{ml}$ against the tested bacteria. The partial nucleotide sequences of the 16S rRNA gene led to identifying both active isolates as Streptomyces species. These active Streptomyces isolates could provide an interesting source for generating innumerable natural compounds with antibacterial activity that can presumably be developed to fight bacterial pathogens in the near future.
\end{abstract}

\section{Introduction}

Foodborne diseases are a vital health public concern that annually affect one-third of people worldwide. WHO reported that the burden of foodborne illness in low-income countries is much higher than in high-income countries [1]. In addition, the WHO reported the highest occurrence of both foodborne diseases and fatality rate in the African and Southeast Asian regions. Global foodborne infection is responsible for 230,000 deaths from 550 million people contracting a foodborne illness from diarrheal diseases yearly, which accounts for $30 \%$ of all deaths in children aged below five years [1].
Streptomyces are well known for their competence to produce thousands of bioactive secondary metabolites and enzymes $[2,3]$. The genus consists of filamentous Grampositive bacteria belonging to the phylum Actinobacteria. The species can grow in a variety of habitats such as soil, marine sediments, and marine sponges $[4,5]$. Copious isolates of Streptomyces have been used to make the majority of natural-derived antibiotics [6]. Consequently, they are regarded as the largest group of microorganisms with medicinal applications, generating more than $50 \%$ of clinically useful antibiotics with antibacterial, antifungal, antiviral, anthelmintic drugs and immune modulators $[7,8]$. Other relevant secondary metabolites produced by Streptomyces 
also exhibit many kinds of biological activities and are used as pharmacological agents and agrobiologicals [9, 10].

The discovery of natural, bioactive compounds with antimicrobial activity may result in the development of novel drugs of choice for treating patients infected with bacterial diseases. Annually, bacterial infections are involved in about 17 million deaths (mostly children and the elderly), while infectious diseases are still the second leading cause of death globally [11]. However, the speedy emergence of resistant bacteria is currently a major public health issue in many parts of the world, especially in developing countries [12]. The outcomes of antibiotic resistance can invoke greater risks of worse clinical consequences for patients, more expensive medical costs, and increased death rates [13-15]. Recent studies have shown the most common, infamous, antibiotic-resistant bacteria which have caused infections in hospitals and communities include Staphylococcus aureus, Enterococcus faecium, Klebsiella pneumoniae, Acinetobacter baumannii, Pseudomonas aeruginosa, and Enterobacter species [16]. People are generally exposed to these drugresistant bacteria via farm animals, aquaculture, and food handlers [17]. Antibiotic resistance often develops due to overuse or misuse of antibiotics and a lack of awareness that this directly promotes the ability of the pathogens to adapt to several common antibiotics. The prevalence of multidrugresistant (MDR) bacterial infections reported from nine provincial hospitals in Northeast Thailand has been recorded as $3-75 \%$ [18], and most of the patients acquired opportunistic infection from the hospitals. Thus, there is an urgent demand for new antibiotics to combat these bacteria. Therefore, this study aimed to isolate Streptomyces from various soil samples in Narathiwat, Southern Thailand, with potent antibacterial activities against pathogenic bacteria. The results of this findings may lead to providing a potential source of new bioactive secondary metabolites.

\section{Materials and Methods}

2.1. Sample Collection and Isolation of Actinomycetes. Thirty soil samples were collected from 3 different sites located in Narathiwat Province, Thailand, in Bacho, Tak Bai, and Yi-ngo districts (Figure 1). The samples were randomly taken from paddy field (10 fields per one area). A trowel was used to delve the soil. Approximately, $100 \mathrm{~g}$ of each soil sample was taken about $10 \mathrm{~cm}$ depth after removing about $3 \mathrm{~cm}$ of the soil surface. These samples were placed in sterile plastic bags, closed tightly, and transferred immediately to the laboratory. Some physicochemical parameters of the soil including texture, color, $\mathrm{pH}$, and moisture content were determined [19, 20]. Later, the samples were air-dried at $45^{\circ} \mathrm{C}$ for $4 \mathrm{~h}$, and subsequently crushed, and sieved. The soil was applied for pretreatment process with drying at $70^{\circ} \mathrm{C}$ for $1 \mathrm{~h}$ in hot air oven. The serial dilution method using preheated soil provided Actinomyces isolates. Briefly, $1 \mathrm{~g}$ of dried soil was suspended in $9 \mathrm{ml}$ sterile distilled water and serially diluted in sterile water up to $10^{-5}$. An aliquot of $0.1 \mathrm{ml}$ of each dilution was spread on a plate of starch casein agar medium (SCA, Himedia, India) supplemented with $25 \mu \mathrm{g} / \mathrm{ml}$ of nalidixic acid (Sigma-Aldrich, USA) and $50 \mu \mathrm{g} /$ $\mathrm{ml}$ of amphotericin B (Sigma-Aldrich, USA) to restrain Gram-negative bacterial and fungal contaminations, respectively. Plates were incubated at $30^{\circ} \mathrm{C}$ for 7-14 days. After the incubation period, each plate was observed for the presence of Actinomycetes colonies that typically have a powdery or adhesive character, with creased or dry features and branching filaments with or without aerial mycelia [21]. The colonies of Actinomyces were re-streaked on yeast extract malt extract agar medium (ISP-2, Himedia, India) and incubated at $30^{\circ} \mathrm{C}$ for $7-14$ days. The pure Actinomyces colonies were individually preserved on an agar slant of ISP2 at $4^{\circ} \mathrm{C}$ and maintained in $25 \%(\mathrm{v} / \mathrm{v})$ glycerol stocks before being stored at $-80^{\circ} \mathrm{C}$ until used.

2.2. Screening of Antibacterial Activity. The antibacterial activity of the Actinomyces isolates was examined by primary screening against the following 5 selected human pathogenic bacteria: Escherichia coli ATCC25922, Salmonella enterica serovar Typhimurium ATCC14028, Pseudomonas aeruginosa ATCC27853, Bacillus cereus MTCC430, and Staphylococcus aureus ATCC25923. The test microorganisms were inoculated in tryptic soy broth (TSB, Himedia, India) at $37^{\circ} \mathrm{C}$ for $18-24 \mathrm{~h}$. The antagonistic assay was initially screened using the cross-streak method [22]. Each isolate of Actinomyces was inoculated on ISP- 2 at $30^{\circ} \mathrm{C}$ for $7-14$ days. It was then re-streaked on Mueller Hinton agar (MHA, Himedia, India) as a direct line in the center of the plate and incubated at $30^{\circ} \mathrm{C}$ for 7 days. Each test pathogenic bacterium was cultured using a streak line perpendicular to the Actinomyces isolates on the same MHA plate and incubated at $35^{\circ} \mathrm{C}$ for $24 \mathrm{~h}$. The inhibitory effect of the Actinomyces isolates against the growth of the tested strains was evaluated using the detection of the inhibition zone, and the results were indicated as follows: $-=$ no activity; $+=$ weak activity ( $<50 \%$ inhibition); $++=$ moderate activity (50-80\% inhibition); and $+++=$ strong activity ( $>80 \%$ inhibition).

2.3. Characterization and Identification of Presumptive Streptomyces Isolates. The effective Actinomycetes obtained from the antibacterial screening were characterized for the presence of Streptomyces using a morphological method, which mainly relied on Gram staining, aerial mass color, and spore formation. Morphological observation was determined by the growth on ISP-2 agar incubated at $30^{\circ} \mathrm{C}$ for 7-14 days and then by microscopic examination of Gram-stained slides. The colors of the aerial mycelia produced by presumptive Streptomyces isolates were compared with the National Bureau of Standards Color Chart [23]. The spore chain arrangement was inspected under oil immersion $(1,000 x)$ using a slide culture method. In addition, identification of the Streptomyces isolates was based on 7 biochemical tests: catalase reaction, urea hydrolysis, $\mathrm{H}_{2} \mathrm{~S}$ production, indole production, citrate degradation, the motility test, and the lysine decarboxylase (LDC) test. The Streptomyces isolates were identified to the genus level according to Bergey's Manual of Systematic Bacteriology [24]. 

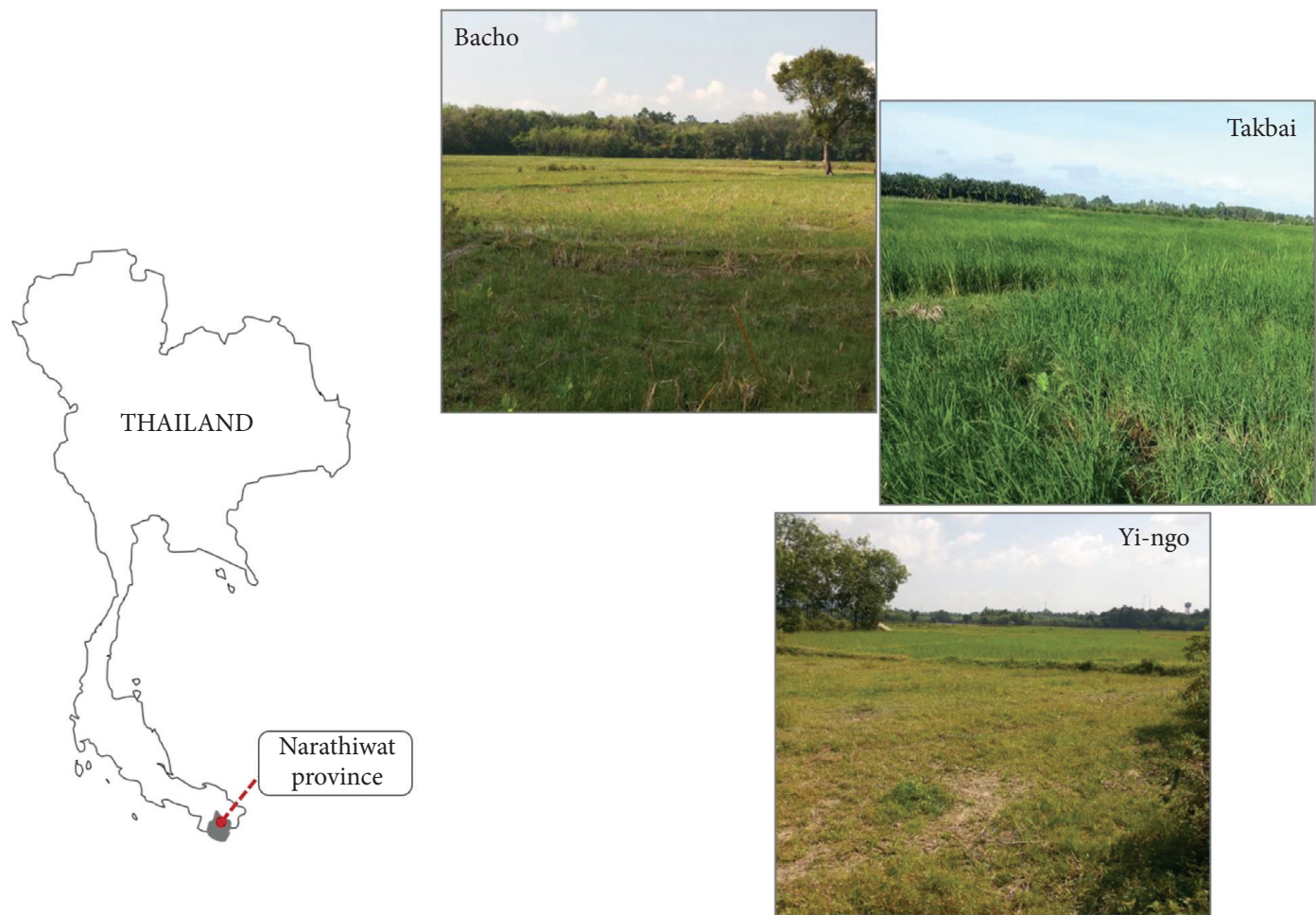

Figure 1: Map and some paddy fields from sampling areas in Bacho, Tak Bai, and Yi-ngo districts.

2.4. Preparation of Crude Extracts. The extraction of active compound was performed following Taechowisan et al. [25] with minor modification. Forty-five $\mathrm{ml}$ of ISP-2 broth was inoculated with $5 \mathrm{ml}$ of spore suspension $\left(1 \times 10^{8}\right.$ spores $\left./ \mathrm{ml}\right)$ of the 10-day-old selected presumptive Streptomyces strains grown on ISP-4 (Himedia, India) plates and incubated at $30^{\circ} \mathrm{C}$ with agitation at $120 \mathrm{rpm}$ for 2 days. After incubation, $50 \mathrm{ml}$ of this culture was aseptically transferred into $450 \mathrm{ml}$ of ISP-2 broth and then incubated for 5 days under the same conditions. The culture broth was filtered through Whatman filter paper to collect the supernatant. Ethyl acetate (J.T.Baker, USA) was added to the supernatant at a ratio of $1: 1(\mathrm{v} / \mathrm{v})$ and shaken vigorously for 2 days. The solvent phase was vaporized to dryness at $50^{\circ} \mathrm{C}$ using a rotary evaporator (Heidolph, Germany). The filtrate of ethyl acetated crude extract was dissolved in $5 \mathrm{ml}$ of acetone, dried, and kept at $4^{\circ} \mathrm{C}$ for further assay.

2.5. Preliminary Test for Bioactive Metabolites of Ethyl Acetate Crude Extracts. The inhibitory effect of the collected crude extracts on the tested bacteria was determined using the agar well diffusion method with slight modifications [26]. Briefly, the bacteria were grown in TSB at $35^{\circ} \mathrm{C}$ for $18-24 \mathrm{~h}$, after which the cell pellet was harvested using centrifugation at $2,000 \times \mathrm{g}$ for $10 \mathrm{~min}$. The pellet was resuspended in $0.85 \%$ normal saline to a final cell density of 0.5 McFarland standards and then was swabbed on the top of MHA plates. A sterile $6 \mathrm{~mm}$ cork borer was used to punch holes in the inoculated plates. The $10 \mathrm{mg} / \mathrm{ml}$ stock extract solution was prepared by dissolving the dry crude extract in 10\% dimethyl sulfoxide (DMSO, Merck, United States), and thereafter
$50 \mu \mathrm{l}$ of each extract was loaded into the holes. The plates were left for $45 \mathrm{~min}$ at room temperature until the extract was completely dispersed into the medium before incubation at $35^{\circ} \mathrm{C}$ for $18-24 \mathrm{~h}$. Each experiment was done in triplicate. The $1 \mathrm{mg} / \mathrm{ml}$ streptomycin (Sigma-Aldrich, USA) and $10 \%$ DMSO served as positive and negative controls, respectively. The diameter of a clear zone surrounding the well was measured in millimeters and the results were later reported as the mean \pm standard deviation of 3 repeats. The presumptive Streptomyces isolates showing more potent antibacterial activities were further selected to determine the minimum inhibitory concentration (MIC) and minimum bactericidal concentration (MBC) of partly purified extracellular crude extracts on the test pathogens.

2.6. Determination of MIC and MBC of Crude Extracts. The MIC and MBC of the ethyl acetate crude extract were evaluated using the colorimetric broth microdilution method with some modifications [27]. The extract was reconstituted in $10 \%$ DMSO solution with distilled water to finally obtain a concentration of $2,048 \mu \mathrm{g} / \mathrm{ml}$. Then, a 2 -fold dilution series of the extract was made with double strength MHB in 96-well, flat-bottomed microtiter plates to eventual concentrations varying from 1 to $1,024 \mu \mathrm{g} / \mathrm{ml}$. An aliquot ( $50 \mu \mathrm{l}$ of $1 \times 10^{6} \mathrm{CFU} / \mathrm{ml}$ ) of tested bacterial suspension was subsequently introduced into the wells. The plate was incubated at $35^{\circ} \mathrm{C}$ for $15 \mathrm{~h}$. The positive control streptomycin $(100 \mu \mathrm{g} / \mathrm{ml})$ and sterility control $(0.85 \% \mathrm{NaCl})$ were included in each test. All assays were conducted in triplicate against the tested inoculum. After the incubation period, $50 \mu \mathrm{l}$ of $0.2 \mathrm{mg} / \mathrm{ml}$ solution of 2,3,5-triphenyl tetrazolium chloride 
(Himedia, India) was loaded in all wells to affirm the growth of bacteria and further incubated at $35^{\circ} \mathrm{C}$ for $3 \mathrm{~h}$. The alteration of the color in the well to pink indicated the presence of bacterial growth, while a lack of any pink color at the lowest concentration of the extract was regarded as the MIC value. In addition, one loop from each dilution that exhibited the growth inhibition was streaked on a TSA plate to note the survival of the pathogens. The concentration of extract resulting in no growth of bacterial colonies on the plate was considered as the MBC value. The degree of inhibition for the MIC determination of extracts was classified based on the following: strong inhibitor, MIC of $<512 \mu \mathrm{g} / \mathrm{ml}$; moderate inhibitor, MIC of $512-1,024 \mu \mathrm{g} / \mathrm{ml}$; and weak inhibitor, MIC of $>1,024 \mu \mathrm{g} / \mathrm{ml}$ [28].

\subsection{Molecular Identification and Sequencing of the $16 \mathrm{~S} r \mathrm{RNA}$} Gene. The selected Streptomyces isolates showing the strong antagonistic activity against tested bacteria were cultured in $1 \mathrm{ml}$ of nutrient broth at $30^{\circ} \mathrm{C}$ for $96 \mathrm{~h}$ with agitation. The pellets were collected using centrifugation at $6,000 \times \mathrm{g}$ for $10 \mathrm{~min}$. The genomic DNA extraction was conducted using QIAamp DNA mini kits (Qiagen, Germany) following the manufacturer's guidance for isolation of genomic DNA from Gram-positive bacteria. PCR amplification of the $16 S r R N A$ gene was performed using universal primers $27 \mathrm{~F}$ and $1492 \mathrm{R}$ [29]. The 1,400-bp 16S rRNA amplicons were purified using a GenepHlow Gel/PCR kit (Geneaid, Taiwan) and were subsequently sequenced (First Base Company, Malaysia) in both forward and reverse directions with the same primers as above. The purified sequences were compared with sequence data deposited in the GenBank database using the NCBI BLAST package.

2.8. Data Analysis. Statistical data analysis was carried out using the SPSS version 26 software package (IBM Corp., USA). The mean comparisons of inhibition zone diameters between the crude extracts and the test pathogens were evaluated using a one-way ANOVA test with Dunnett T3 as post hoc analysis. Statistical outcomes with $P<0.05$ were considered statistically significant.

\section{Results}

3.1. Sample Collection and Isolation of Actinomycetes. The data of physicochemical properties of the 30 soil samples collected from three locations in Narathiwat are presented in Table 1. The distribution of Actinomycete isolates was found in those samples. In total, 136 Actinomycete isolates were grown on SCA medium (Table 1), of which 45 (33.09\%), 57 (41.91\%), and 34 (25.00\%) Actinomycetes were isolated from Bacho, Tak Bai, and Yi-ngo soil samples, respectively.

3.2. Screening of Antibacterial Activity. All 136 Actinomyces isolates were screened for antagonistic activity against 5 selected bacterial pathogens. Among them, only 19 isolates $(13.97 \%)$ were active isolates (Table 2 ) and of these, 14 isolates (73.68\%) could strongly inhibit the growth of $B$. cereus
MTCC430, while 12 isolates (63.16\%) had the strongest inhibition against $S$. aureus ATCC25923, 8 isolates weakly or moderately suppressed the growth of E. coli ATCC25922, and 2 isolates had a weak inhibitory effect on the growth of $S$. enterica serovar Typhimurium ATCC14028. None of the isolates could inhibit the growth of $P$. aeruginosa ATCC27853. The most sensitive bacteria to metabolites produced by these Actinomycetes were B. cereus MTCC430 and S. aureus ATCC25923; consequently, they were selected for further testing.

3.3. Characterization and Presumptive Identification of Streptomyces Isolates. The 19 active Actinomyces isolates were primarily classified as Streptomyces based on their morphological appearance including colors of aerial mycelium and the presence of spore formation. Four colors of aerial mycelium were identified, with most isolates being gray ( 9 isolates; $47.37 \%$ ), white ( 6 isolates; $31.58 \%$ ), or yellow ( 3 isolates; $15.79 \%$ ) as shown in Table 3 . The slide cultures revealed diverse shapes of spore chains depending on each isolate with spiral, rectiflexibile, and retinaculiaperti; however, most isolates $(42.11 \%)$ had retinaculiaperti spore chains. The biochemical characteristics of all isolates are shown in Table 3. These isolates were Gram-positive and produced catalase. No isolates produced indole or $\mathrm{H}_{2} \mathrm{~S}$. The degradation of citrate and urea was noted in some isolates. All isolates were non-motile and negative for the LDC test.

\subsection{Preliminary Test for Bioactive Metabolites of Ethyl Acetate} Crude Extracts. The 7 isolates with high antagonistic activity against S. aureus ATCC25923 and B. cereus MTCC430 were chosen to determine the bioactive metabolites of their filtrate crude extracts. Two of them (isolates 1BAC-7 and 12BAC-7) exhibited good activity against the tested bacteria with inhibition zone diameters ranging from $8.17 \pm 0.29$ to $13.00 \pm 0.00 \mathrm{~mm}$ (Table 4 and Figure 2).

3.5. Determination of $M I C$ and $M B C$ of Crude Extracts. The results of MIC and MBC of the crude extracts against S. aureus ATCC25923 and B. cereus MTCC430 are given in Table 4. Two extracts of note were 1BAC-7FE with a high MIC value $(512 \mu \mathrm{g} / \mathrm{ml})$ which was classified as a moderate inhibitor for S. aureus ATCC25923 and B. cereus MTCC430, whereas 12BAC-7FE with an MIC value of $256 \mu \mathrm{g} / \mathrm{ml}$ was regarded as a strong inhibitor. It was observed that crude extract from isolate 1BAC-7 had no antibacterial activity with its $\mathrm{MBC}$ values being higher than $1,024 \mu \mathrm{g} / \mathrm{ml}$ against S. aureus ATCC25923, while 12BAC-7FE had a high value of MBC $(512 \mu \mathrm{g} / \mathrm{ml})$. Furthermore, the extract of isolate $12 \mathrm{BAC}-7$ had a lower MBC value $(256 \mu \mathrm{g} / \mathrm{ml})$ than $1 \mathrm{BAC}-$ 7FE against $B$. cereus MTCC430. The standard antibiotic streptomycin had MIC and MBC values of 3.13 and $6.25 \mu \mathrm{g} /$ $\mathrm{ml}$, respectively, against the tested pathogenic bacteria.

3.6. Molecular Identification and Sequencing of the 16S rRNA Gene. The partial DNA sequences amplified from presumptive Streptomyces isolates 7BAC-1, 11BAC-7, 2BAC10, 4TAK-5, 9TAK-5, 1BAC-7, and 12BAC-7 were analyzed 
TABle 1: Physicochemical characteristics and abundance of Actinomycete isolates found in soil samples at diverse sampling areas.

\begin{tabular}{lccccc}
\hline Soil samples $^{\mathrm{a}}$ & \multicolumn{3}{c}{ Parameters } \\
& Texture & Color & pH range & Moisture content (\%) range & No. of Actinomycete isolates (\%) \\
\hline BAC-1 to BAC-10 & Loam, clay loam & Brown & $3.7-4.1$ & $15.5-28.1$ & $45(33.09)$ \\
TAK-1 to TAK-10 & Clay & Gray, brown & $4.6-5.2$ & $23.6-37.9$ & $57(41.91)$ \\
YIN-1 to YIN-10 & Loam & Brown & $4.0-5.2$ & $16.8-24.5$ & $34(25)$ \\
\hline
\end{tabular}

${ }^{a}$ The soil samples were named with sampling sites and the number of paddy fields. BAC: Bacho; TAK: Tak Bai; YIN: Yi-ngo.

TABLE 2: Primary antibacterial screening of 19 potent Actinomyces isolates against 5 pathogenic bacteria using the cross-streak method.

\begin{tabular}{|c|c|c|c|c|c|c|}
\hline \multirow{2}{*}{ No. } & \multirow{2}{*}{ Isolates $^{\mathrm{a}}$} & \multicolumn{5}{|c|}{ Degree of inhibition against tested bacterial pathogens ${ }^{b}$} \\
\hline & & EC & ST & $\mathrm{PA}$ & SA & $\mathrm{BC}$ \\
\hline 1 & 7BAC-1 & - & - & - & +++ & +++ \\
\hline 2 & $11 \mathrm{BAC}-1$ & - & - & - & +++ & + \\
\hline 3 & 5BAC-6 & - & - & - & +++ & + \\
\hline 4 & 1BAC-7 & - & - & - & +++ & +++ \\
\hline 5 & 11BAC-7 & - & + & - & +++ & +++ \\
\hline 6 & $12 \mathrm{BAC}-7$ & - & - & - & +++ & +++ \\
\hline 7 & 16BAC-7 & - & - & - & + & + \\
\hline 8 & 9BAC-9 & - & - & - & + & + \\
\hline 9 & $2 \mathrm{BAC}-10$ & - & + & - & +++ & +++ \\
\hline 10 & 9TAK-1 & - & - & - & +++ & +++ \\
\hline 11 & 1TAK-3 & + & - & - & - & + \\
\hline 12 & 4TAK-5 & ++ & - & - & +++ & +++ \\
\hline 13 & 9TAK-5 & - & - & - & +++ & +++ \\
\hline 14 & $11 \mathrm{TAK}-6$ & ++ & - & - & - & - \\
\hline 15 & 1TAK-8 & ++ & - & - & - & - \\
\hline 16 & 2TAK-8 & + & - & - & - & ++ \\
\hline 17 & 1YIN-1 & + & - & - & - & - \\
\hline 18 & 4YIN-2 & + & - & - & - & - \\
\hline \multirow[t]{2}{*}{19} & 5YIN-2 & ++ & - & - & - & - \\
\hline & Total & 8 & 2 & 0 & 12 & 14 \\
\hline
\end{tabular}

${ }^{a}$ The code name of isolates was designated as the number of isolates found in each soil sample. ${ }^{\mathrm{b}}$ EC: E. coli ATCC25922; ST: S. enterica serovar Typhimurium ATCC14028; PA: P. aeruginosa ATCC27853; BC: B. cereus MTCC430; SA: S. aureus ATCC25923; +++: strong activity; ++: moderate activity; +: weak activity; -: no activity.

TABle 3: Morphological features and biochemical characteristics of presumptive Streptomyces isolates.

\begin{tabular}{|c|c|c|c|c|c|c|c|c|c|c|}
\hline \multirow[b]{2}{*}{ Isolates } & \multicolumn{2}{|c|}{$\begin{array}{l}\text { Morphological and cultural } \\
\text { characteristics }\end{array}$} & \multirow[b]{2}{*}{$\begin{array}{l}\text { Gram } \\
\text { stain }\end{array}$} & \multirow[b]{2}{*}{$\begin{array}{l}\text { Catalase } \\
\text { reaction }\end{array}$} & \multirow[b]{2}{*}{$\begin{array}{c}\text { Indole } \\
\text { production }\end{array}$} & \multicolumn{2}{|c|}{ Biochemical test ${ }^{\mathrm{a}}$} & \multirow[b]{2}{*}{$\begin{array}{c}\text { Urease } \\
\text { hydrolysis }\end{array}$} & \multirow[b]{2}{*}{$\begin{array}{c}\text { Motility } \\
\text { test }\end{array}$} & \multirow[b]{2}{*}{$\begin{array}{c}\text { LDC } \\
\text { test }\end{array}$} \\
\hline & $\begin{array}{c}\text { Aerial } \\
\text { mass } \\
\text { color }\end{array}$ & $\begin{array}{c}\text { Spore } \\
\text { arrangement }\end{array}$ & & & & $\begin{array}{c}\text { Citrate } \\
\text { degradation }\end{array}$ & $\begin{array}{c}\mathrm{H}_{2} \mathrm{~S} \\
\text { production }\end{array}$ & & & \\
\hline 7BAC-1 & White & Spiral & + & + & - & + & - & + & - & - \\
\hline $\begin{array}{l}11 \mathrm{BAC}- \\
1\end{array}$ & Gray & Rectiflexibile & + & + & - & - & - & - & - & - \\
\hline $5 B A C-6$ & Gray & Rectiflexibile & + & + & - & - & - & - & - & - \\
\hline 1BAC-7 & Gray & Spiral & + & + & - & + & - & + & - & - \\
\hline $\begin{array}{l}11 \mathrm{BAC}- \\
7\end{array}$ & Gray & Spiral & + & + & - & + & - & + & - & - \\
\hline $\begin{array}{l}12 \mathrm{BAC}- \\
7\end{array}$ & Gray & Spiral & + & + & - & + & - & + & - & - \\
\hline $\begin{array}{l}\text { 16BAC- } \\
7\end{array}$ & Gray & Spiral & + & + & - & + & - & + & - & - \\
\hline 9BAC-9 & Gray & Retinaculiaperti & + & + & - & + & - & + & - & - \\
\hline $\begin{array}{l}2 \mathrm{BAC}- \\
10\end{array}$ & Gray & Retinaculiaperti & + & + & - & - & - & + & - & - \\
\hline 9TAK-1 & White & Retinaculiaperti & + & + & - & - & - & - & - & - \\
\hline $1 \mathrm{TAK}-3$ & White & Spiral & + & + & - & - & - & - & - & - \\
\hline 4TAK-5 & White & Retinaculiaperti & + & + & - & + & - & + & - & - \\
\hline
\end{tabular}


TABLE 3: Continued.

\begin{tabular}{|c|c|c|c|c|c|c|c|c|c|c|}
\hline \multirow[b]{2}{*}{ Isolates } & \multicolumn{2}{|c|}{$\begin{array}{l}\text { Morphological and cultural } \\
\text { characteristics }\end{array}$} & \multirow[b]{2}{*}{$\begin{array}{l}\text { Gram } \\
\text { stain }\end{array}$} & \multirow[b]{2}{*}{$\begin{array}{l}\text { Catalase } \\
\text { reaction }\end{array}$} & \multirow[b]{2}{*}{$\begin{array}{l}\text { Indole } \\
\text { production }\end{array}$} & \multicolumn{2}{|c|}{ Biochemical test $\mathrm{t}^{\mathrm{a}}$} & \multirow[b]{2}{*}{$\begin{array}{l}\text { Urease } \\
\text { hydrolysis }\end{array}$} & \multirow[b]{2}{*}{$\begin{array}{l}\text { Motility } \\
\text { test }\end{array}$} & \multirow[b]{2}{*}{$\begin{array}{c}\text { LDC } \\
\text { test }\end{array}$} \\
\hline & $\begin{array}{c}\text { Aerial } \\
\text { mass } \\
\text { color }\end{array}$ & $\begin{array}{c}\text { Spore } \\
\text { arrangement }\end{array}$ & & & & $\begin{array}{c}\text { Citrate } \\
\text { degradation }\end{array}$ & $\begin{array}{c}\mathrm{H}_{2} \mathrm{~S} \\
\text { production }\end{array}$ & & & \\
\hline 9TAK-5 & White & Rectiflexibile & + & + & - & + & - & + & - & - \\
\hline $\begin{array}{l}11 \mathrm{TAK}- \\
6\end{array}$ & Yellow & Retinaculiaperti & + & + & - & - & - & + & - & - \\
\hline 1TAK-8 & Gray & Retinaculiaperti & + & + & - & + & - & + & - & - \\
\hline 2TAK-8 & Orange & Retinaculiaperti & + & + & - & - & - & + & - & - \\
\hline 1YIN-1 & White & Retinaculiaperti & + & + & - & - & - & - & - & - \\
\hline 4YIN-2 & Yellow & Rectiflexibile & + & + & - & - & - & - & - & - \\
\hline $5 Y I N-2$ & Yellow & Spiral & + & + & - & - & - & - & - & - \\
\hline
\end{tabular}

${ }^{a}+$ : positive; -: negative; LDC test: lysine decarboxylase test.

TABLE 4: Antibacterial property of crude extracts against selected pathogenic bacteria determined using the agar well diffusion assay and colorimetric broth microdilution method.

\begin{tabular}{|c|c|c|c|c|}
\hline \multirow{2}{*}{ Crude extract and control } & \multicolumn{2}{|c|}{ Diameter of the inhibition zone (mm) } & \multicolumn{2}{|c|}{$\mathrm{MIC} / \mathrm{MBC}(\mu \mathrm{g} / \mathrm{ml})$} \\
\hline & SA & $\mathrm{BC}$ & SA & $\mathrm{BC}$ \\
\hline $7 \mathrm{BAC}-1 \mathrm{FE}$ & $0.00 \pm 0.00^{c}$ & $0.00 \pm 0.00^{c}$ & nd & nd \\
\hline 1BAC-7FE & $8.17 \pm 0.29^{\mathrm{a}}$ & $9.33 \pm 1.15^{\mathrm{a}}$ & $512 />1024$ & $512 / 512$ \\
\hline 11BAC-7FE & $0.00 \pm 0.00^{c}$ & $0.00 \pm 0.00^{c}$ & nd & nd \\
\hline 12BAC-7FE & $8.83 \pm 0.29^{\mathrm{a}}$ & $13.00 \pm 0.00^{\mathrm{ab}}$ & $256 / 512$ & $256 / 256$ \\
\hline 2BAC-10FE & $0.00 \pm 0.00^{\mathrm{c}}$ & $0.00 \pm 0.00^{c}$ & nd & nd \\
\hline $4 \mathrm{TAK}-5 \mathrm{FE}$ & $0.00 \pm 0.00^{c}$ & $0.00 \pm 0.00^{c}$ & nd & nd \\
\hline 9TAK-5FE & $0.00 \pm 0.00^{\mathrm{c}}$ & $0.00 \pm 0.00^{c}$ & nd & nd \\
\hline Streptomycin & $19.50 \pm 0.87^{\mathrm{b}}$ & $26.50 \pm 3.04^{\mathrm{b}}$ & $3.13 / 6.25$ & $3.13 / 6.25$ \\
\hline
\end{tabular}

Data are expressed as mean \pm SD of 3 replicates. Results with different lowercase superscripts in the same column are significantly different at $P<0.05$ (Dunnett' T3 test). FE: filtrate of the ethyl acetate crude extract; SA: S. aureus ATCC25923; BC: B. cereus MTCC430; nd: not determined.

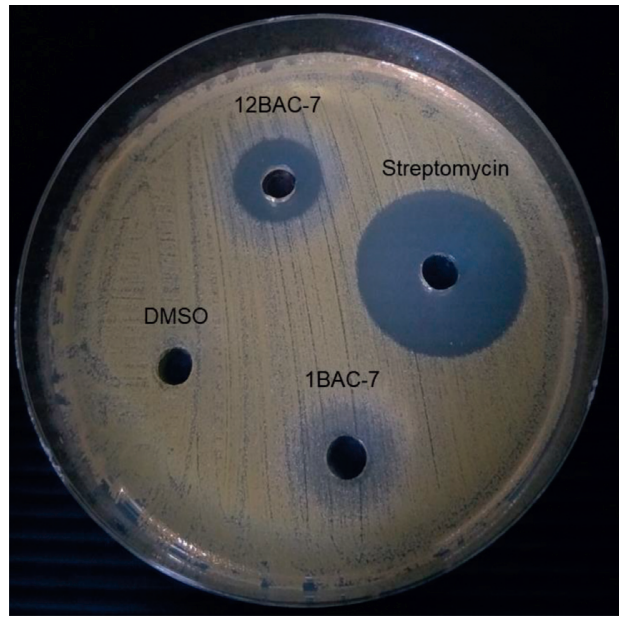

(a)

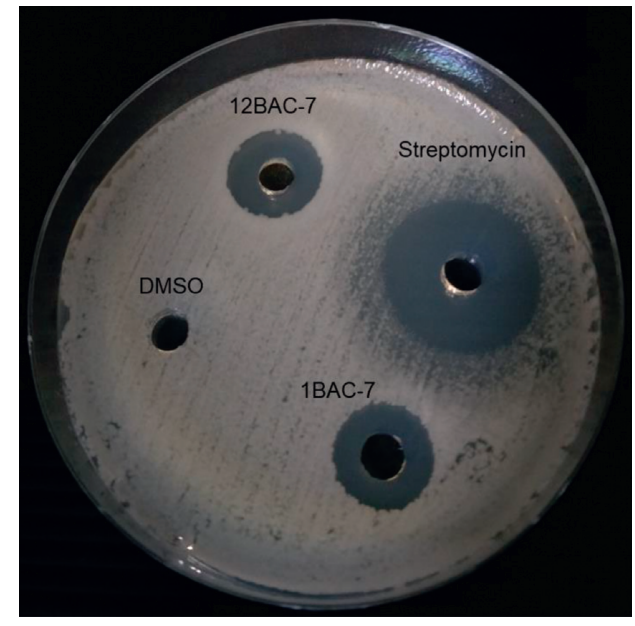

(b)

Figure 2: Inhibitory effect of 1BAC-7FE and 12BAC-7FE against S. aureus ATCC25923 (a) and B. cereus MTCC430 (b) determined using the agar well diffusion method with the positive $(1 \mathrm{mg} / \mathrm{ml}$ streptomycin) and negative control (10\% DMSO).

using a BlastN search. The results indicated that these isolates were identified as Streptomyces spp. with $99.3-100 \%$ similarity and their GenBank accession numbers were recorded as MZ389213, MZ389214, MZ389215, MZ389216, MZ389217, MT373689, and MT373690, respectively.

\section{Discussion}

A great effort to identify new bioactive substances is necessary because of their advantages in the treatment of currently infectious diseases resulting from multidrug- 
resistant pathogens. Streptomycetes belonging to the family Actinobacteria are well known worldwide for the important production of broad-spectrum secondary metabolites $[30,31]$. In the present study, 30 soil samples taken from rice fields in 3 districts of Narathiwat province were investigated for the presence of Actinomycetes. The prevalence of 136 Actinomyces isolates was the greatest at Tak Bai (41.91\%) followed by Bacho (33.09\%) and Yi-ngo (25\%) districts. This is the first report exploring soil Actinomycetes in the southernmost province of Thailand. A previous study conducted in Thailand detected 50 Actinomyces isolates from 6 soil samples collected from Chonburi province [32]. In another study, 123 isolates of Actinomycetes were found from 37 forest soil samples in Nakhon Ratchasima province, Thailand [33]. Actinomycetes are widespread in soils rich in organic matter and can grow on the surface layer of the soil at depths of 5-10 cm [34]. Our results proved that all isolates of Actinomycetes were widely distributed in acidic soil with $\mathrm{pH}$ between 3.7 and 5.2, and moderate moisture range from $15.5 \%$ to $37.9 \%$ which corresponds with the previous reports [35-37]. Assorted factors affecting the population density of Actinomycetes in soil samples include $\mathrm{pH}$, temperature, and soil water content [8]. The current findings based on the screening of antibacterial activity identified that 19 isolates (13.97\%) primarily exhibited encouraging antibacterial activity toward the studied pathogenic bacteria. Most of the active isolates could strongly inhibit the growth of $S$. aureus ATCC25923 and B. cereus MTCC430, whereas some Actinomyces isolates had weak or moderate activity against E. coli ATCC25922 and S. enterica serovar Typhimurium ATCC14028. However, P. aeruginosa ATCC27853 was the most insensitive bacteria. Sapkota et al. [38] reported that $44.8 \%$ of the isolated Streptomyces spp. had activity against S. aureus, and $10.3 \%$ had activity against E. coli and $K$. pneumonia, with none having activity against $P$. aeruginosa. These results indicated the dissimilar sensitivity between Gram-positive and Gram-negative bacteria due to the distinctive structural components of their cell walls. Gram-positive bacteria have merely the peptidoglycan layer that does not prevent the penetration of bioactive compounds. On the other hand, Gram-negative bacteria have an outer membrane composed of lipopolysaccharide constituents which provide an efficient blockade to lipophilic solutes and contribute to greater resistance to those compounds [39]. Considering the morphological and biochemical characteristics of the 19 active isolates of Actinomyces in the current study, their typical features were in accordance with a member of the genus Streptomyces. Thus, all isolates were presumptively identified as Streptomyces isolates. Moreover, the gray color of the aerial mycelium was the most predominant (47.37\%) followed by white series (31.58\%). This was consistent with previous findings that reported gray and white color series were a principal group isolated from soil $[40,41]$. Among the active isolates, 7 selected isolates that showed strong inhibitory effects against B. cereus MTCC430 and S. aureus ATCC25923 were subsequently evaluated for their capability to secrete diffusible bioactive metabolites of filtrate crude extracts based on agar well diffusion assay. The results demonstrated that the antagonistic effects of the crude extracts 12BAC-7FE and 1BAC-7FE against $S$. aureus ATCC25923 were significantly lower than standard streptomycin. However, the mean of inhibition zone of 12BAC-7FE against B. cereus MTCC430 was not significantly different to the positive control. The remaining 5 extracts did not have any zones of inhibition against the tested pathogenic bacteria, which contrasted with their antibacterial activity on the agar plate obtained during the primary screening. The results were in agreement with Abussaud et al. [40] that found only 5 of 8 active isolates having activity on agar medium produced antagonistic effects in broth culture. These results may be attributed to differences in the culture media composition, inoculum size, or growth conditions that influence the ability of Streptomyces isolates to secrete different active substances on solid growth surfaces and liquid media $[8,42]$. Another possible explanation is that some active metabolites discharged by streptomycetes may be destroyed or chemically altered during the solvent extraction process $[8,42]$. The extraction of the culture filtrate derived from Streptomyces strains using ethyl acetate was utilized broadly to regain powerful secondary metabolites. Lim et al. [43] reported the strongest anti-MDR bacterial activity was from ethyl acetate extracts attained from soil Streptomyces. In addition, the ethyl acetate extracts of Streptomyces anulatus NEAE-94 had the highest inhibitory effects against multidrug-resistant $S$. aureus compared to other solvent extractions [44]. In the current study, the inhibitory activity of isolate 12BAC-7 against S. aureus ATCC25923 and B. cereus MTCC430 was evidently stronger than the ethyl acetate crude extract acquired from the isolate 1BAC-7; nevertheless, these 2 active isolates were clearly proven to be Streptomyces species with high similarity on the basis of $16 S$ rRNA gene sequence analysis. The comparison of our findings to the results of an earlier study reveals that the crude ethyl acetate extract of Streptomyces sp. FEAI-1 showed a notably higher degree of inhibition against both $S$. aureus and B. cereus, with MIC and MBC values comprised in the range of $15.6-125 \mu \mathrm{g} / \mathrm{ml}$ and $62.5-250 \mu \mathrm{g} /$ $\mathrm{ml}$, respectively [45]. It might be due to the difference of the cultural condition used in the experiments which had an effect on the production of active metabolites. Wang et al. [46] reported diverse parameters of process such as temperature, incubation time, carbon, and nitrogen sources that exert an influence on the secondary metabolites production. Further studies on the optimization of growing conditions and nutritional requirements of both 12BAC-7 and 1BAC-7 isolate are needed for improving the antibacterial metabolite production. In addition, the metabolite crude extracts should also be structurally characterized by means of HPLCMS to identify the active compounds that may be useful for future development into novel therapeutic agents.

\section{Conclusion}

Our study focused on searching for new, useful bioactive metabolites from soil-derived Actinomycetes. The 2 potent Streptomyces spp. (isolates 1BAC-7 and 12BAC-7) were isolated from 30 different paddy soils collected in 3 areas of Narathiwat province, Southern Thailand. Although, the 
ethyl acetate crude extracts formed by both isolates had moderate to strong inhibition against Gram-positive S. aureus ATCC25923 and B. cereus MTCC430, an isolate of Streptomyces sp. (12BAC-7) should be considered as a promising source of effective metabolites against the selected test pathogens.

\section{Data Availability}

The data used in this study are included within the article, and the sequence data are available from the NCBI nucleotide database.

\section{Conflicts of Interest}

The authors declare that there are no conflicts of interest.

\section{Authors' Contributions}

WC and SD designed the study and assisted with writing and editing of the manuscript. WC and WBI carried out the experiment and analyzed the data. All authors read and approved the final manuscript.

\section{Acknowledgments}

This work was financially supported by the Faculty of Medicine, Princess of Naradhiwas University (Med. internal grant 2019). The authors extend their thanks to Dr. Andrew John Warner for English corrections in this manuscript.

\section{References}

[1] World Health Organization, WHO, WHO Estimates of the Global Burden of Foodborne Diseases, World Health Organization, Geneva, Switzerland, 2015.

[2] V. Behal, "Bioactive products from Streptomyces," Advances in Applied Microbiology, vol. 47, pp. 113-156, 2000.

[3] K. J. P. Narayana and M. Vijayalakshmi, "Chitinase production by Streptomyces sp. ANU 6277," Brazilian Journal of Microbiology, vol. 4, pp. 725-733, 2009.

[4] H. Maleki, A. Dehnad, S. Hanifian, and S. Khani, "Isolation and molecular identification of Streptomyces spp. with antibacterial activity from Northwest of Iran," BioImpacts: BI, vol. 3, pp. 129-134, 2013.

[5] F. M. Rashad, H. M. Fathy, A. S. El-Zayat, and A. M. Elghonaimy, "Isolation and characterization of multifunctional Streptomyces species with antimicrobial, nematicidal and phytohormone activities from marine environments in Egypt," Microbiological Research, vol. 175, pp. 34-47, 2015.

[6] J. Hug, C. Bader, M. Remškar, K. Cirnski, and R. Müller, "Concepts and methods to access novel antibiotics from Actinomycetes," Antibiotics, vol. 7, no. 2, p. 44, 2018.

[7] J. Mann, "Natural products as immunosuppressive agents," Natural Product Reports, vol. 18, no. 4, pp. 417-430, 2001.

[8] E. A. Barka, P. Vatsa, L. Sanchez et al., "Taxonomy, physiology, and natural products of Actinobacteria," Microbiology and Molecular Biology Reviews, vol. 80, no. 1, pp. 1-43, 2016.

[9] V. Duraipandiyan, A. H. Sasi, V. I. H. Islam, M. Valanarasu, and S. Ignacimuthu, "Antimicrobial properties of actinomycetes from the soil of Himalaya," Journal de Mycologie Médicale, vol. 20, no. 1, pp. 15-20, 2010.

[10] S. B. Zotchev, "Marine actinomycetes as an emerging resource for the drug development pipelines," Journal of Biotechnology, vol. 158, no. 4, pp. 168-175, 2012.

[11] World Health Organization, WHO, The Top 10 Causes of Death, World Health Organization, Geneva, Switzerland, 2018, http://www.who.int/news-room/fact-sheets/detail/thetop-10-causes-of-death.

[12] J. A. Ayukekbong, M. Ntemgwa, and A. N. Atabe, "The threat of antimicrobial resistance in developing countries: causes and control strategies," Antimicrobial Resistance and Infection Control, vol. 6, no. 1, p. 47, 2017.

[13] S. E. Cosgrove, K. S. Kaye, G. M. Eliopoulous, and Y. Carmeli, "Health and economic outcomes of the emergence of thirdgeneration cephalosporin resistance in Enterobacter species," Archives of Internal Medicine, vol. 162, no. 2, pp. 185-190, 2002.

[14] A. Borer, L. Saidel-Odes, K. Riesenberg et al., "Attributable mortality rate for carbapenem-resistant Klebsiella pneumoniae bacteremia," Infection Control \& Hospital Epidemiology, vol. 30, no. 10, pp. 972-976, 2009.

[15] N. D. Friedman, E. Temkin, and Y. Carmeli, "The negative impact of antibiotic resistance," Clinical Microbiology and Infections, vol. 22, no. 5, pp. 416-422, 2016.

[16] H. W. Boucher, G. H. Talbot, J. S. Bradley et al., "Bad bugs, no drugs: no ESKAPE! an update from the Infectious Diseases Society of America," Clinical Infectious Diseases, vol. 48, no. 1, pp. 1-12, 2009.

[17] O. A. Odeyemi and N. A. Sani, "Antibiotic resistance and burden of foodborne diseases in developing countries," Future Science OA, vol. 2, no. 4, p. FSO139, 2016.

[18] C. Lim, E. Takahashi, M. Hongsuwan et al., "Epidemiology and burden of multidrug-resistant bacterial infection in a developing country," Elife, vol. 5, Article ID e18082, 2016.

[19] W. Horwitz, Official Methods of Analysis, AOAC International, Gaithersburg, MD, USA, 17th edition, 2000.

[20] E. Semu and D. Akishule, "Growth of Streptomyces isolates from four soils in Morogoro, Tanzania, under culture-media $\mathrm{pH}$ conditions other than their original environmental $\mathrm{pH}$," Tanzania Journal of Natural and Applied Sciences, vol. 2, pp. 424-432, 2011.

[21] T. J. Mincer, P. R. Jensen, C. A. Kauffman, and W. Fenical, "Widespread and persistent populations of a major new marine actinomycete taxon in ocean sediments," Applied and Environmental Microbiology, vol. 68, no. 10, pp. 5005-5011, 2002.

[22] M. A. Rahman, M. Z. Islam, and M. A. Islam, “Antibacterial activities of actinomycete isolates collected from soils of Rajshahi, Bangladesh," Biotechnology Research International, vol. 2011, Article ID 857925, 6 pages, 2011.

[23] H. Zhao, R. L. Parry, D. I. Ellis, G. W. Griffith, and R. Goodacre, "The rapid differentiation of Streptomyces isolates using Fourier transform infrared spectroscopy," $V i$ brational Spectroscopy, vol. 40, no. 2, pp. 213-218, 2006.

[24] P. Kampfer, "Genus streptomyces," in Bergey's Manual of Systematic Bacteriology: The Actinobacteria, M. Goodfellow, P. Kampfer, H.-J. Busse et al., Eds., pp. 1455-1767, Springer, New York, NY, USA, 2nd edition, 2012.

[25] T. Taechowisan, C. Lu, Y. Shen, and S. Lumyong, "Secondary metabolites from endophytic Streptomyces aureofaciens CMUAc130 and their antifungal activity," Microbiology, vol. 151, no. 5, pp. 1691-1695, 2005. 
[26] G. Gebreyohannes, F. Moges, S. Sahile, and N. Raja, "Isolation and characterization of potential antibiotic producing actinomycetes from water and sediments of Lake Tana, Ethiopia," Asian Pacific Journal of Tropical Biomedicine, vol. 3, no. 6, pp. 426-435, 2013.

[27] Clinical and Laboratory Standards Institute, CLSI., "Methods for dilution antimicrobial susceptibility tests for bacteria that grow aerobically," in Approved Standard, Clinical and Laboratory Standards Institute, Pittsburgh, PA, USA, 10th edition, 2015.

[28] N. Aligiannis, E. Kalpoutzakis, S. Mitaku, and I. B. Chinou, "Composition and antimicrobial activity of the essential oils of two origanum species," Journal of Agricultural and Food Chemistry, vol. 49, no. 9, pp. 4168-4170, 2001.

[29] P. S. Kumar, J. P. P. Raj, V. Duraipandiyan, and S. Ignacimuthu, "Antibacterial activity of some actinomycetes from Tamil Nadu, India," Asian Pacific Journal of Tropical Biomedicine, vol. 2, no. 12, pp. 936-943, 2012.

[30] S. I. Patzer and V. Braun, "Gene cluster involved in the biosynthesis of griseobactin, a catechol-peptide siderophore of Streptomyces sp. ATCC 700974," Journal of Bacteriology, vol. 192 , no. 2 , pp. $426-435,2010$.

[31] S. T. Khan, H. Komaki, K. Motohashi et al., "Streptomyces associated with a marine sponge Haliclona sp.; biosynthetic genes for secondary metabolites and products," Environmental Microbiology, vol. 13, no. 2, pp. 391-403, 2011.

[32] P. Sripreechasak and A. Athipornchai, "Potential antimicrobial properties of Streptomyces isolated from sammuk mountain soil, Chonburi province, Thailand," Journal of Advanced Pharmaceutical Technology \& Research, vol. 10, pp. 195-199, 2019.

[33] P. Chanthasena and N. Nantapong, "Biodiversity of antimicrobial-producing actinomycetes strains isolated from dry dipterocarp forest soil in northeast Thailand," Brazilian Archives of Biology and Technology, vol. 59, Article ID e16150674, 2016.

[34] G. S. H. Bonjar, "Screening for antibacterial properties of some Iranian plants against two strains of Escherichia coli," Asian Journal of Plant Sciences, vol. 3, no. 3, pp. 310-314, 2004.

[35] J. Y. Lee and B. K. Hwang, "Diversity of antifungal actinomycetes in various vegetative soils of Korea," Canadian Journal of Microbiology, vol. 48, no. 5, pp. 407-417, 2002.

[36] N. Poomthongdee, K. Duangmal, and W. Pathom-aree, "Acidophilic actinomycetes from rhizosphere soil: diversity and properties beneficial to plants," Journal of Antibiotics, vol. 68, no. 2, pp. 106-114, 2015.

[37] A. Borowik and J. Wyszkowska, "Soil moisture as a factor affecting the microbiological and biochemical activity of soil," Plant Soil and Environment, vol. 62, no. 6, pp. 250-255, 2016.

[38] A. Sapkota, A. Thapa, A. Budhathoki, M. Sainju, P. Shrestha, and S. Aryal, "Isolation, characterization, and screening of antimicrobial-producing actinomycetes from soil samples," International Journal of Microbiology, vol. 2020, Article ID 2716584, 7 pages, 2020.

[39] T. Sibanda, L. V. Mabinya, N. Mazomba et al., "Antibiotic producing potentials of three freshwater actinomycetes isolated from the Eastern Cape Province of South Africa," International Journal of Molecular Sciences, vol. 11, no. 7, pp. 2612-2623, 2010.

[40] M. J. Abussaud, L. Alanagreh, and K. Abu-Elteen, "Isolation, characterization and antimicrobial activity of Streptomyces strains from hot spring areas in the northern part of Jordan," African Journal of Biotechnology, vol. 12, pp. 7124-7132, 2013.
[41] P. S. Kumar, V. Duraipandiyan, and S. Ignacimuthu, "Isolation, screening and partial purification of antimicrobial antibiotics from soil Streptomyces sp. SCA 7," The Kaohsiung Journal of Medical Sciences, vol. 30, no. 9, pp. 435-446, 2014.

[42] I. Charousova, J. Medo, L. Hleba, M. Cisarova, and S. Javorekova, "Antimicrobial activity of actinomycetes and characterization of actinomycin-producing strain KRG-1 isolated from Karoo, South Africa," Brazilian Journal of Pharmaceutical Sciences, vol. 55, Article ID e17249, 2019.

[43] S. S. Lim, A. Selvaraj, Z. Y. Ng et al., "Isolation of actinomycetes with antibacterial activity against multi-drug resistant bacteria," Malaysian Journal of Microbiology, vol. 14, pp. 293-305, 2018.

[44] N. E.-A. El-Naggar, A. A.-A. El-Bindary, M. Abdel-Mogib, and N. S. Nour, "In vitro activity, extraction, separation and structure elucidation of antibiotic produced by Streptomyces anulatus NEAE-94 active against multidrug-resistant Staphylococcus aureus," Biotechnology \& Biotechnological Equipment, vol. 31, no. 2, pp. 418-430, 2017.

[45] M. F. Khatun, M. U. Haque, and M. A. U. Islam, "Antibacterial and cytotoxic activities of crude ethyl acetate extract of Streptomyces sp. FEAI-1 isolated from soil samples of Rajshahi, Bangladesh," Bangladesh Pharmaceutical Journal, vol. 20, no. 2, pp. 188-193, 2018.

[46] Y. Wang, X. Fang, F. An, G. Wang, and X. Zhang, "Improvement of antibiotic activity of Xenorhabdus bovienii by medium optimization using response surface methodology," Microbial Cell Factories, vol. 10, no. 1, p. 98, 2011. 